\title{
The Interaction of Trait Competitiveness and Leaderboard Design - An Experimental Analysis of Effects on Perceptions and Usage Intention
}

\author{
Christoph E. Höllig \\ Technical University of Munich \\ christoph.hoellig@tum.de
}

\author{
Andranik Tumasjan \\ Technical University of Munich \\ andranik.tumasjan@tum.de
}

\author{
Isabell M. Welpe \\ Technical University of Munich \\ welpe@tum.de
}

\begin{abstract}
Gamification is a valuable approach to foster user engagement, raise motivation, and induce behavioral change. As a maturing field of research, the complex interactions of the various elements of gameful systems remain opaque. However, understanding these interactions, especially between user and gamified system, builds the foundation for the vast application of gamified systems. To advance our knowledge in this field, we employ an experimental research design with 192 participants. Thereby we show that users' personal development competitiveness positively affects the perception and usage intention of a competitive gamified system in a work scenario. Further, this relationship is moderated by the system's design. Focusing on a team-based rather than a player-based leaderboard supports the usage intentions and perceptions of individuals high in personal development competitiveness. Our study supports the need for individualized gameful systems rather than relying on one-system-fits-all approaches often found in business practice.
\end{abstract}

\section{Introduction}

In the last years, gamification has become a heavily debated topic $[19,47]$ and is increasingly facilitated to foster user motivation and engagement in various settings - ranging from education, innovation, employee engagement, crowdsourcing to marketing. Gamification, early described as "the use of game design elements in non-game contexts" [11, p. 10], aims to motivate and support "by adding a hedonic element to the activity: providing, for example, feedback, achievable goals, progress, and encouragement" [19, p. 180]. The approach thereby underlies the consideration to foster user engagement through features evident in digital games beyond entertainment [34].
Recently, Nacke and Deterding pointed out, that gamification research is maturing, transiting from fundamental "what?" and "why?" questions to more differentiated questions about the implementation of gamification: "how?", "when?", and "how and when not?" [38]. Accordingly, the maturation of gamification research is accompanied with more finegrained definitions. For instance, Huotari and Hamari define gamification from a service marketing perspective as "a process of enhancing a service with affordances for gameful experiences in order to support users' overall value creation" and thus unbound it from specific game design elements and rather focus on its inherent goals: affording gameful experiences and supporting the overall value creation [26, p. 25].

While striving for the outcomes of gamification, the interaction of the various determinants of gamified systems, such as player types and game mechanics, is frequently discussed. For instance, Preist et al. show, based on qualitative interview data from a proenvironmental crowdsourcing study, that different attitudes toward a leaderboard may result in different and even negative behavioral outcomes and thus call for cautious design of competitive gamified systems [41]. This is inter-connected with our yet nonexhaustive understanding of player types i.e. the relationship of player traits and behavior found in games and gamified applications, so far mostly based on qualitative research approaches and lacking the empirical segmentation of players (exceptions can be found, e.g. [54, 55]) [20].

In order to advance gamification research regarding this impediment, the goal of our study is to assess whether perception and usage intention of gamified systems varies between people based on their trait competitiveness. In particular, we assess in an experimental vignette study placed in a work scenario, how individual differences in personal development competitiveness determine perceptions (i.e. how a system is perceived regarding e.g. its usefulness) and usage intention (i.e. the self-assessed intention to use the system) of competitive gamified systems. Further, we test for an interaction of this effect with the specific 
design of the gamified system. More specifically, whether an employed leaderboard shows the performance of a team (team-based) or the performance of a single player (player-based). Our study also addresses the constantly stated need for a better understanding of users in the use of gamified systems (e.g. [17, 33, 35]), and work contexts [7].

\section{Competitive Gamification}

Gamification aims at increasing motivation and inducing behavioral change by the use of design principles underlying games in order to make tasks more fun and enjoyable [12]. Such game design elements include, for example, mechanics such as points, leaderboards, and levels [56]. These mechanics, based on the individual reaction of the user, then result in game dynamics such as challenge, empathy, or competition [6]. One of the most commonly used game elements are leaderboards [29]. For instance, crowdsourcing systems that strive to accomplish homogeneous repetitive tasks commonly employ leaderboard-based game designs [37].
However, empirical evidence regarding the effectiveness of leaderboards, i.e. inducing a competitive game environment is ambivalent. Although some studies indicate positive effects of the employment of leaderboards [8, 14, 15, 31, 32], others show no, mixed or negative effects $[13,21,34,36,57]$ (see Table 1). Eickhoff et al. hint at "moderate success" of an implemented leaderboard to encourage competition in an annotation game [14, p. 9]. Hanus and Fox tested the appliance of game elements including a leaderboard in order to flourish motivation, social comparison, effort and satisfaction in a classroom course through a gamified curriculum but reported negative outcomes [21]. Zuckerman and Gal$\mathrm{Oz}$ compare three versions of an application aimed to promote routine walking, one employing a leaderboard, in two field studies but found no difference in effectiveness [57].

Some studies attributed varying results of leaderboards i.e. competition to individual differences between users. Hamari et al. report in their literature review, based on freeform feedback of several of the examined studies, that some users regarded some game

Table 1. Overview of empirical studies on the effects of leaderboards.

\begin{tabular}{|c|c|c|c|}
\hline Ref. & Measure & Result & $\mathrm{N}$ \\
\hline [8] & $\begin{array}{l}\text { Performance on a math test in a virtual classroom } \\
\text { (male-dominated vs. female-dominated vs. non- } \\
\text { leaderboard condition) }\end{array}$ & $\begin{array}{l}\text { Leaderboards can (positively) affect academic } \\
\text { performance }\end{array}$ & 80 \\
\hline [32] & $\begin{array}{l}\text { Time-on-task and academic performance in an online } \\
\text { wiki-based project (leaderboard vs. non-leaderboard } \\
\text { condition) }\end{array}$ & $\begin{array}{l}\text { Leaderboard increases } \\
\text { frequency of interaction }\end{array}$ & 86 \\
\hline [31] & $\begin{array}{l}\text { Performance in a brainstorming task (leaderboard vs. } \\
\text { easy goal vs. difficult goal vs. impossible goal vs. } \\
\text { "do your best" condition) }\end{array}$ & $\begin{array}{l}\text { Leaderboard was successful in motivating } \\
\text { participants to performance levels similar to that } \\
\text { of difficult and impossible goal-setting }\end{array}$ & 339 \\
\hline [13] & $\begin{array}{l}\text { Performance on assignments in an e-learning } \\
\text { environment (gamified vs. non-gamified condition) }\end{array}$ & $\begin{array}{l}\text { Gamified experience (including a leaderboard) } \\
\text { led to better overall scores, but poor performance } \\
\text { on written assignments and participation }\end{array}$ & 123 \\
\hline [15] & $\begin{array}{l}\text { User participation on a social networking site } \\
\text { (gamified vs. non-gamified condition) }\end{array}$ & $\begin{array}{l}\text { Temporal rise in user contributions due to a point } \\
\text { system including a leaderboard }\end{array}$ & 126 \\
\hline [21] & $\begin{array}{l}\text { Motivation, social comparison, effort, satisfaction, } \\
\text { learner empowerment, and academic performance of } \\
\text { students in a 16-weeks course (gamified vs. non- } \\
\text { gamified condition) }\end{array}$ & $\begin{array}{l}\text { Students in the gamified course (including a } \\
\text { badges-based leaderboard) showed less } \\
\text { motivation, satisfaction, and empowerment over } \\
\text { time }\end{array}$ & 80 \\
\hline [34] & $\begin{array}{l}\text { Performance and intrinsic motivation in an image } \\
\text { annotation task (plain vs. points vs. levels vs. } \\
\text { leaderboard condition) }\end{array}$ & $\begin{array}{l}\text { Leaderboards increase performance. No effect on } \\
\text { intrinsic motivation was found }\end{array}$ & 273 \\
\hline [57] & $\begin{array}{l}\text { Walking Time of users of an experimental activity } \\
\text { app (quantified vs. points vs. leaderboard condition) }\end{array}$ & $\begin{array}{l}\text { The leaderboard version yielded similar results as } \\
\text { the quantified (control) condition }\end{array}$ & 95 \\
\hline [36] & $\begin{array}{l}\text { Performance of sales personnel at a startup company } \\
\text { (game vs. control vs. leaderboard condition) }\end{array}$ & $\begin{array}{l}\text { Leaderboard condition performed significantly } \\
\text { worse than the other conditions }\end{array}$ & 233 \\
\hline [14] & $\begin{array}{l}\text { Performance in crowdsourcing tasks (HITs) } \\
\text { (gamified vs. non-gamified condition) }\end{array}$ & $\begin{array}{l}\text { Moderate success of employed leaderboard } \\
\text { (crowd workers produce free annotations) }\end{array}$ & 795 \\
\hline
\end{tabular}


elements such as those encouraging competition, as negative [19]. Furthermore, Codish and Ravid show in a classroom setting, that extraverted students perceived leaderboards as less playful [9]. Contrastingly, Jia et al. indicate, in a study using the big five personality traits, positive correlations of extraversion with leaderboards [28]. This finding is backed by Jia et al., showing, based on a survey, that more extroverted people report more positive experience with leaderboards, unregarded the application domain [27].

Although the outlined studies hint to the importance of individual differences in the perception of competitive gamified systems, the phenomenon is not yet fully understood. Consequently, gameful systems are complex, bringing together the systems motivational affordances, individual dispositions and application domain. The vast application opportunities of competitive game mechanics, therefore rely on the explanation of how the different elements of a gamified system interact with each other. Especially, since these interactions may also result in negative effects.

\section{Trait Competitiveness}

Trait competitiveness, "the enjoyment of interpersonal competition and the desire to win and be better than others" [50, p. 41], may serve as a valuable means to differentiate user perceptions and usage intentions of gamified systems employing competitive game mechanics. As a personality trait, trait competitiveness is generally applicable, time-stable, and is rarely subject to sudden changes or discontinuities [50]. According to Housten et al., two general and more fine-grained constructs underlie trait competitiveness, labeled self-aggrandizement, and interpersonal success [24]. Our study focuses on the interpersonal success component of competitiveness, which is linked to personal development (i.e., helps one to improve oneself) rather than winning as the utmost importance. Individuals, high in personal development competitiveness see competitors as facilitators who grant them with opportunities for personal growth and self-discovery. In a team setting, these individuals would therefore rather compete for team functioning and development, than primarily focusing on winning against other team members [44, 45].

Although substantial research on the role of trait competitiveness with regard to competitive contexts in video games exist, to our knowledge no empirical research is available exploring this phenomenon in a gamification setting. For instance, Vorderer et al. find evidence that individuals with a competitive disposition showed a slight preference for games that grant the opportunity to express one's competitiveness [53]. Song et al. show that for highly competitive individuals, competition in an exergame (a portmanteau of "exercise" and "games") increased intrinsic motivation, but low competitiveness was detrimental for intrinsic motivation [49]. Although fullfledged video games differ from the principles of gamification, which rather foresee providing a gaming layer on existing activities and services, the outlined studies show the significance of trait competitiveness. We expect that users of gamified systems, high in personal development competitiveness, may thrive in competitive mechanics and value the system as means for self-development and growth. Therefore, these users may percept a competitive gamified system e.g. as more enjoying than others do. Vice versa, we expect that less competitive individuals may experience competitive mechanics in a negative way. Thus:

Hla. Personal development competitiveness positively influences the perceptions of a competitive gamified system.

Further, we expect that also their intention to use a system fostering their thriving for self-development and growth, differ:

H1b. Personal development competitiveness positively influences the usage intention of a competitive gamified system.

Considering outcomes such as enjoyment as a result of user-system-interaction (e.g., [6]), a mere observation of individual differences is not sufficient to determine the perceptions and usage intention of a gamified system. Rather, the design of the system including the employed game mechanics has to be included in the observation. As competitive mechanics can be shaped in different ways, a crucial design decision is choosing a player-based or a team-based leaderboard. For instance, when the consulting firm Slalom Consulting implemented a mobile application including a player-based leaderboard to motivate employees to learn each other's names and faces, only five percent participated. This changed, when they transformed to teams, leading to a jump to ninety percent participation rate due to the fact that employees did not want to let their teams down [30]. But not only can reshaping a competitive gamified system from player-based to team-based competition lead to positive effects. Also, vice versa, intra-team competition, e.g. induced by a player-based leaderboard, is positively related to team conflict [5]. Ryckman et al. find, that individuals high in personal development competitiveness are more concerned with the welfare of others and thus place greater value on the shared experiences of the group [45]. Further, these individuals are generally social-oriented [44], show 
tendencies towards cooperative behavior [42] and are high in self-esteem [23].

As winning seems not of utmost importance considering their high self-esteem and social concerns, we expect individuals, high in personal development competitiveness to likely subordinate their own interests to those of the group and to rather disregard the possibilities of team conflict. We propose the following:

H2a. Game mechanics will moderate the positive effects of personal development competitiveness on perceptions of a competitive gamified system such that perceptions are higher when the gamified system facilitates a group-based leaderboard.

$H 2 b$. Game mechanics will moderate the positive effects of personal development competitiveness on the usage intention of a competitive gamified system such that usage intention is higher when the gamified system facilitates a group-based leaderboard.

For the concluding research model see Figure 1.

Figure 1. Research model.

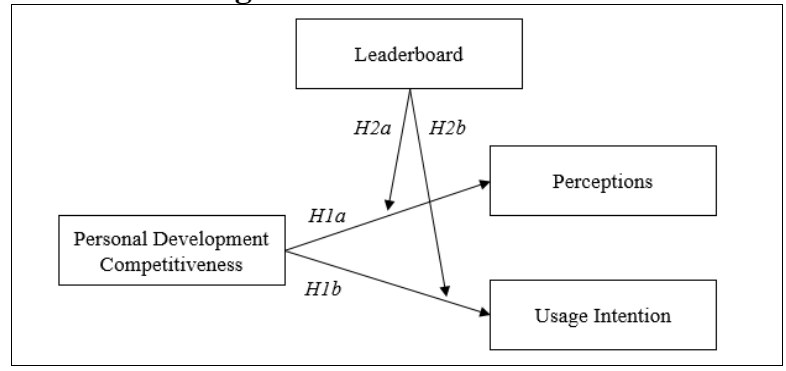

\section{Methodology \& Data}

To test our hypotheses, we conducted an experimental vignette study. A vignette is "a short, carefully constructed description of a person, object, or situation, representing a systematic combination of characteristics" [4, p. 128]. Vignette studies are especially suitable to study the influence of independent variables on beliefs, attitudes or intentions as dependent variables [2]. In addition, they are high in internal validity and can increase external validity due to an experimental and realistic design [4].

A between-subjects factorial research design was chosen with two factors, a team-based, and a playerbased leaderboard. Participants were randomly assigned to a vignette, which in the first part displays a constructed situation: "Your company uses an internal information system, which basically includes the intranet and other software tools for your and the teams' daily work. Recently, your company adopted and integrated a gamified system Gamely into the company information systems. Gamely may assist for example in employee personal progress monitoring".
And further describes a gamified system, in which a participant is either placed on a player-based leaderboard, competing with every other employee in the company, or on a team-based leaderboard, competing with his/her team with other work teams: "With the monthly collected score of points you and your team work together to secure a placement on a team-leaderboard. Below you can see an example of your gamified profile in the described situation". Further, a mockup showing the described gamified system and a team-based or player-based leaderboard was shown (see Figure 2). Participants were then surveyed regarding their perceptions and usage intention towards the gamified system, followed by a manipulation check and questions regarding participants' trait competitiveness and demographic information.

Figure 2. Mockup of team-based leaderboard.

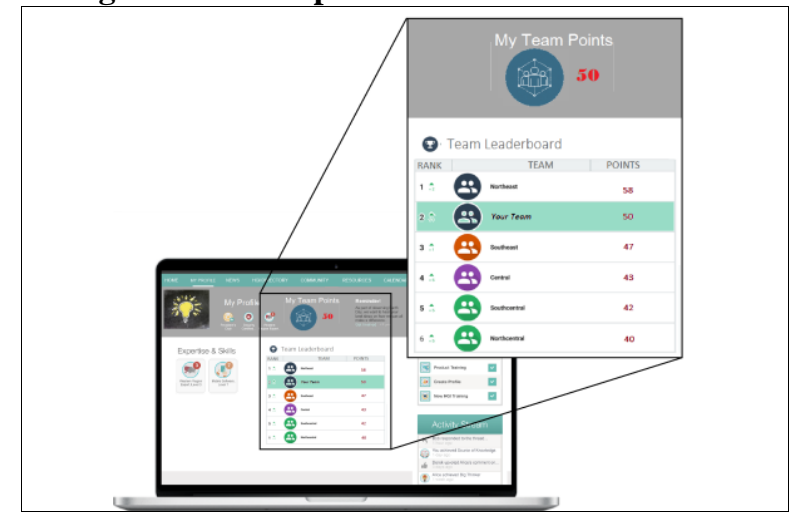

\subsection{Participants}

The participants were recruited online to complete the study in April/May 2017. Of the valid responses, 21 were excluded which did not pass the manipulation check. The manipulation check ensured in one question that participants had a clear understanding of the introduced leaderboard. Participants were questioned whether the described gamified system included a leaderboard based on the performance of their work team or on their individual performance. The final population sample (see Table 2) consisted of $\mathrm{N}=192$ participants, of which $83(43.23 \%)$ were in the playerbased leaderboard and $102(56.77 \%)$ in the team-based leaderboard condition. We conducted independent samples Chi-squared and Mann-Whitney-U tests to test for differences between the groups. We found no significant differences in gender $\left(\chi^{2}=0.842, p=\right.$ $0.359)$, nationality $\left(\chi^{2}=0.017, p=0.896\right)$, employment status $\left(\chi^{2}=5.176, p=0.159\right)$, age $(U=4389.0, p=$ $0.286)$ or education ( $U=3999.5, p=0.063)$ between the groups. 
Table 2. Descriptive statistics of participants - frequencies (and percentages) are reported.

\begin{tabular}{|c|c|c|c|c|c|c|}
\hline \multirow{2}{*}{$\overline{\text { Gender }}$} & \multicolumn{2}{|c|}{$\begin{array}{l}\text { Player-based Leaderboard } \\
(n=83)\end{array}$} & \multicolumn{2}{|c|}{$\begin{array}{l}\text { Team-based Leaderboard } \\
(n=109)\end{array}$} & \multicolumn{2}{|c|}{$\begin{array}{l}\text { Total } \\
N=192\end{array}$} \\
\hline & & & & & & \\
\hline Male & 28 & $(33.7)$ & 45 & $(41.3)$ & 73 & $(38.0)$ \\
\hline Female & 55 & (66.3) & 64 & (58.7) & 119 & $(62.0)$ \\
\hline \multicolumn{7}{|l|}{ Age } \\
\hline $20-29$ & 72 & $(86.8)$ & 91 & $(83.5)$ & 163 & $(85.0)$ \\
\hline $30-39$ & 9 & (10.8) & 17 & (15.6) & 26 & (13.5) \\
\hline $40-49$ & 1 & $(1.2)$ & 1 & $(0.9)$ & 2 & $(1.0)$ \\
\hline $50+$ & 1 & $(1.2)$ & 0 & $(0.0)$ & 1 & $(0.5)$ \\
\hline \multicolumn{7}{|l|}{ Nationality } \\
\hline Europe & 63 & (75.9) & 80 & $(73.4)$ & 143 & (74.5) \\
\hline Others & 20 & $(24.1)$ & 29 & $(26.6)$ & 49 & (25.5) \\
\hline \multicolumn{7}{|l|}{ Education } \\
\hline Secondary School & 14 & (16.9) & 14 & (12.8) & 28 & (14.6) \\
\hline Bachelor's Level & 40 & $(48.2)$ & 65 & (59.6) & 105 & (54.7) \\
\hline Master's Level & 28 & (33.7) & 29 & $(26.6)$ & 57 & (29.7) \\
\hline Doctorate & 1 & $(1.2)$ & 1 & $(0.9)$ & 2 & $(1.0)$ \\
\hline \multicolumn{7}{|l|}{ Employment Status } \\
\hline Student & 51 & (61.5) & 72 & $(66.0)$ & 123 & $(64.1)$ \\
\hline Job-Seeking & 5 & $(6.0)$ & 7 & $(6.4)$ & 12 & (6.3) \\
\hline Employed & 26 & (31.3) & 23 & (21.1) & 49 & (25.5) \\
\hline Self-Employed & 1 & $(1.2)$ & 7 & $(6.4)$ & 8 & $(4.2)$ \\
\hline
\end{tabular}

The "Nationality" category "Others" comprises 19 countries with under 5 respondents each.

\subsection{Measurements}

The constructs used in our study were adapted from previously published sources. Following Koivisto and Hamari, we chose constructs representing social, hedonic, and utilitarian benefits of gamification [29]. Moreover, usage intention was measured. Further, we based them on 7-point Likert-Scales (1: strongly disagree - 7: strongly agree).

Playfulness. Playfulness describes the belief to which extent creative and explorative behavior would occur in user-system interaction and is measured on a nine-item scale (adapted from [18, 22, 51]), including items such as "I would find the described Gamely playful" and "I would find the described Gamely uninventive".

Enjoyment. This four-item measure describes the degree of expected enjoyment when using the information system (adapted from [10, 18, 22]) and includes items such as "I would find the described Gamely interesting" and "I would find the described Gamely exciting".

Usefulness. Usefulness measures the level of expected benefits for work performance when using the gamified system on five items (adapted from [10,
$18,51])$. The measure includes items such as "Using the described Gamely would make it easier for me to perform my work in the company" and "I would feel more effective with regards to my work when using the described Gamely".

Reciprocal Benefits. Reciprocal benefits describes on a four-item scale the expected degree of social benefits received from other workers using the gamified system (adapted from [25, 29]) and includes items such as "I think that using the described Gamely could be advantageous to me and other people" and "I think that using the described Gamely could be mutually helpful".

Recognition. Recognition describes in four items the social motivation drawn from the belief that others value own actions when using the gamified system (adapted from [25, 29]) and is measured in items such as "I would like it when my colleagues noticed my achievements in the described Gamely" and "I would feel good when my achievements in the described Gamely were noticed".

Usage Intention. Usage intention measures on a three-item scale the degree to which the gamified system is believed to be used (adapted from [1, 52]). Items include "Given that I had access to the described Gamely, I predict that I would use it" and "Assuming I 
had access to the described Gamely, I expect that I would use it".

Personal Development Competitiveness. We chose a measure that reflects our working definition of competitiveness. Personal development competitiveness measures the attitude that values personal improvement such as self-knowledge and the expression of potentials and abilities gained from competition over winning itself [24] and thus describes the interpersonal success component of trait competitiveness. It was assessed on a 15-item reliable self-report measure designed to assess the individual strength of trait competitiveness based on personal development goals (based on [44]). The scale includes items such as "I enjoy competition because it brings me to a higher level of motivation to bring out the best in myself rather than as a means of doing better than others", "I enjoy competition because it brings me and my competitors closer together as human beings" and "I enjoy competition because it gives me a chance to discover my abilities".

For all measures, convergent validity and reliability, as well as discriminant validity, were assessed and deemed as acceptable (see Table 3). Average variance extracted (AVE), composite reliability (CR) and Cronbach's alpha) exceeded conventional cutoffs $[16,39]$. In order to guarantee that all items loaded with their corresponding constructs above 0.650 level, we omitted items that loaded too poorly. Five items of the competitiveness construct and six items of the playfulness construct were omitted. Furthermore, discriminant validity was assessed. For each construct, the square root of its AVE has to exceed its correlation with every other construct [16]. Further, inter-correlations between constructs were lower than 0.9 [40].

\section{Results}

We tested our hypotheses using hierarchical regression analyses. For the hierarchical regression, we used a controls-only model (including gender, age, education, employment status, nationality) as our baseline model. No significant main effects of the control variables were found. The inclusion of personal development competitiveness and its interaction with gamification design explained more variance in the perceptions and usage intention towards a competitive gamified system compared to our baseline model (e.g. for usage intention: $R^{2}=0.298$ versus 0.035 ).

Significant main effects of personal development competitiveness for all dependent variables were found. More specifically, personal development competitiveness, influenced the perceptions of playfulness $(\beta=.389, p<.001)$, enjoyment $(\beta=.473, p$ $<.001)$, usefulness $(\beta=.524, p<.001)$, reciprocal benefits $(\beta=.533, p<.001)$, and recognition $(\beta=.482$, $p<.001)$. Thus, hypothesis 1a, regarding the perceptions of competitive gamified was supported.

Besides main effects, significant interaction effects of personal development competitiveness and gamification design, i.e. whether a team-based or a player-based leaderboard is employed, were found. These interaction effects were found for enjoyment $(\beta$ $=.143, p<.05)$, reciprocal benefits $(\beta=.135, p<.05)$ and usage intention $(\beta=.148, p<.05)$. Thus, hypothesis $2 \mathrm{a}$ was partly supported and hypothesis $2 \mathrm{~b}$ was supported.

To better understand the pattern of the interaction between personal development competitiveness and gamification design on usage intention, we plotted the significant interactions by following Aiken and West's

Table 3. Correlation matrix, validity, and reliability.

\begin{tabular}{llllllll}
\hline & $\mathrm{P}$ & $\mathrm{E}$ & $\mathrm{U}$ & $\mathrm{RB}$ & $\mathrm{R}$ & $\mathrm{UI}$ & $\mathrm{PDC}$ \\
\hline Playfulness (P) & $\mathbf{. 7 6 5}$ & & & & & & \\
Enjoyment (E) & .628 & $\mathbf{. 8 5 2}$ & & & & & \\
Usefulness (U) & .577 & .821 & $\mathbf{. 8 6 8}$ & & & & \\
Reciprocal Benefits (RB) & .658 & .836 & .841 & $\mathbf{. 8 8 0}$ & & & \\
Recognition (R) & .445 & .651 & .642 & .677 & $\mathbf{. 8 6 0}$ & & \\
Usage Intention (UI) & .500 & .793 & .718 & .771 & .592 & $\mathbf{. 9 4 4}$ & \\
Personal Development & .414 & .491 & .532 & .539 & .500 & .498 & $\mathbf{. 7 7 8}$ \\
Competitiveness (PDC) & & & & & & & \\
\hline Mean & 4.80 & 4.70 & 4.33 & 4.73 & 4.95 & 4.86 & 4.39 \\
SD & 1.14 & 1.38 & 1.41 & 1.42 & 1.37 & 1.50 & 1.29 \\
\hline AVE & .585 & .725 & .754 & .774 & .740 & .891 & .605 \\
Alpha & .809 & .913 & .939 & .932 & .918 & .961 & .938 \\
\hline N & .808 & .915 & .939 & .931 & .917 & .961 & .938 \\
\hline
\end{tabular}

$N=192$. Square roots of AVEs are reported in bold in the diagonal.

$A V E$ should be greater than 0.5. CR should be greater than 0.6. Cronbach's alpha should be great than 0.7. 
Table 4. Hierarchical regression analyses - $\beta$-coefficient is reported.

\begin{tabular}{|c|c|c|c|c|c|c|}
\hline & Playfulness & Enjoyment & Usefulness & $\begin{array}{l}\text { Reciprocal } \\
\text { Benefits }\end{array}$ & Recognition & $\begin{array}{l}\text { Usage } \\
\text { Intention }\end{array}$ \\
\hline \multicolumn{7}{|l|}{ Baseline model } \\
\hline \multicolumn{7}{|l|}{ Control Variables } \\
\hline$\Delta R^{2}$ & .035 & .038 & .030 & .032 & .069 & .035 \\
\hline \multicolumn{7}{|l|}{ Step 1} \\
\hline $\begin{array}{l}\text { Personal Development } \\
\text { Competitiveness }\end{array}$ & $.389^{* * *}$ & $.473 * * *$ & $.524 * * *$ & $.533 * * *$ & $.482 * * *$ & $.497 * * *$ \\
\hline$\Delta R^{2}$ & .146 & .214 & .266 & .277 & .235 & .232 \\
\hline \multicolumn{7}{|l|}{ Step 2} \\
\hline Gamification Design & -.058 & .052 & -.016 & -.013 & $-.141 *$ & .104 \\
\hline$\Delta R^{2}$ & .003 & .003 & .000 & .000 & .020 & .010 \\
\hline \multicolumn{7}{|l|}{ Step 3} \\
\hline $\begin{array}{l}\text { Personal Development } \\
\text { Competitiveness } \times \\
\text { Gamification Design }\end{array}$ & .033 & $.143^{*}$ & $.101 \dagger$ & $.135^{*}$ & .099 & $.148^{*}$ \\
\hline$\Delta R^{2}$ & .001 & .019 & .012 & .018 & .009 & .021 \\
\hline$R^{2}$ & .185 & .274 & .308 & .327 & .333 & .298 \\
\hline Adj. $R^{2}$ & .140 & .234 & .270 & .290 & .296 & .259 \\
\hline$F$ & $4.11^{* * * *}$ & $6.84 * * *$ & $8.05^{* * *}$ & $8.78 * * *$ & $9.04 * * *$ & $7.68^{* * *}$ \\
\hline
\end{tabular}

$N=192$. Gamification Design: Team-based Leaderboard condition was coded with the higher variable value. Control variables include age, nationality, gender, education and employment status.

$\dagger p<.10 . * p<.05 . * * p<.01 . * * * p<.001$.

guidelines [3]. Figure 3 shows the plot of the described interaction. Usage intention is especially valuable as it describes the behavioral outcomes indicated by the participants. In this vein, the interaction shows, that individuals high in personal development competitiveness, would rather use the competitive gamified system employing a team-based leaderboard.

\section{Figure 3. Interaction effects on Usage Intention}

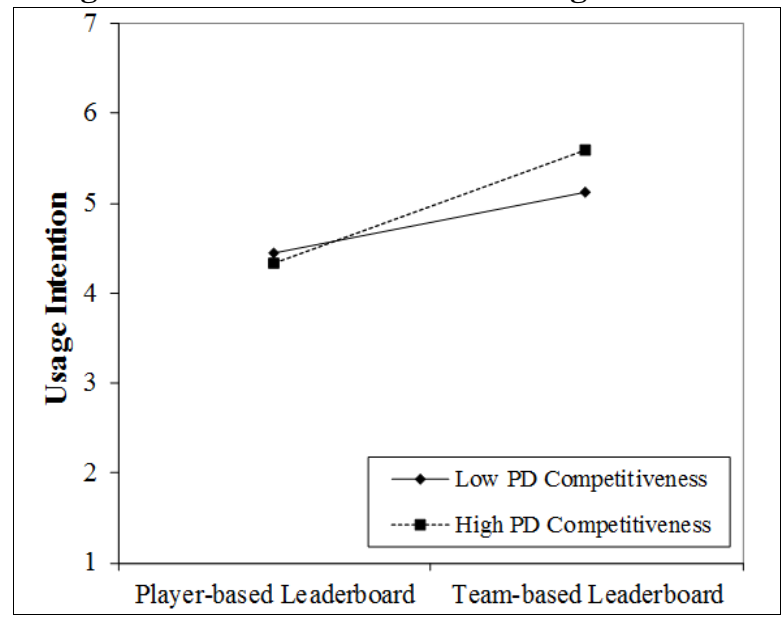

\section{Discussion}

We tested the effect of both user's trait competitiveness and the effects of its interaction with gamification design, i.e. the design of a leaderboard on perceptions and usage intention of a competitive gamified system in a work scenario.

\subsection{Theoretical Contributions}

Our results show, that individuals high in personal development competitiveness, have greater perceptions of and greater intention to use a competitive gamified system. More specifically, competitive individuals regard these systems as more playful, useful and enjoying. According to Ross et al., personal development competitiveness is positively related to extraversion [42]. Therefore, our findings are comparable with previous findings, showing that extroverted people report higher preferences towards and more positive experience with leaderboards unregarded the application domain [27, 28]. Furthermore, we find that competitive individuals regard reciprocal benefits of competitive gamified systems higher and value it more to be recognized by other users. Drawing on the connection of personal 
development competitiveness and extraversion [42], this is comparable with findings in social media use, which show that extroverts have a tendency to express one's actual self on social media [48].

Our results further indicate that the effects of personal development competitiveness on perceptions and usage intentions of a competitive gamified system are moderated by a facet of a gamified system's design, i.e. whether the used leaderboard shows the performance of a team or the performance of a single player. Individuals high in personal development competitiveness regard a gamified system, including a team-based leaderboard, more enjoying and value its reciprocal benefits higher. According to Ryckman et al., individuals high in personal development competitiveness, endorse values associated with social concern, i.e. care about the well-being of others [45]. Thus, it is conceivable that these individuals regard team-based leaderboards as a means to satisfy their need to treat others equally and with respect. On the other hand, player-based leaderboards may be regarded as potentially detrimental to an individual's social environment. Recognition, playfulness, and usefulness, were not affected by the design of the leaderboard. It is conceivable, that playfulness and usefulness are rather regarded as statically given by the overall system by the participants, with no anticipated gain in usefulness or playfulness by just slightly changing the design of the leaderboard. In regards to recognition, not only no moderation-effects were shown, but also significant negative effects of the design itself could be measured. This is understandable, since team-based leaderboards may impede the opportunity to receive value from others on own actions, as actions are not anymore distinguishable between each individual and rather become group-actions. As researchers have considered leaderboards as supporting the need for status and recognition [13], our findings suggest that leaderboards may also be designed in a way to actively neglect these needs.

\subsection{Practical Implications}

Our findings bear valuable design implications for the design of competitive gamified systems in a work context. First, trait competitiveness is a strong predictor whether an individual may use a competitive gamified system. Thus, designers should consider a pre-evaluation of the competitiveness of a potential user group before deciding about the utilization of leaderboards or other competitive game mechanics. Second, the design decision between a team-based or a player-based leaderboard is crucial as it affects the perceptions and usage intentions of individuals, competing for self-development and achievement, rather than winning itself. Therefore, these individuals may rather refuse to use competitive gamified systems, using a player-based leaderboard, and thus do not foster their need for social coherence. Lastly, experimental vignette studies, as facilitated in this study, may serve as a valuable tool to pre-determine the preferences of users towards a gamified system. Thus, they may be used for individualizing gamified systems, adapting to the individual preferences of its users, e.g. by hiding out game elements, after the user self-evaluated his/her preferences in an automated vignette study, that do not suit the preference of the user.

\subsection{Limitations \& Future Research}

Measurements in the vignette study were selfreported and self-selected. Therefore, the results may represent individuals which like the idea of gamification and thus are eager to participate in research around it. This issue could be addressed by future studies, e.g. employed in a laboratory setting when drawing participants without knowledge about the study's topic, but based on an eagerness to participate in research in general or in order to earn money. This is also related to the fact that the study's data is gathered from the general population. In order to further understand gamification in a work scenario, studies with a focus on company personnel should be facilitated, including a company's cultural setting, and specifics of the individual work setting, e.g. the team size or work mode, as control variables.

Another limitation of our study is, that we tested only one dimension of trait competitiveness. More specifically, we tested a dimension of trait competitiveness related to self-development. This was driven by the consideration, that leaderboards, as a competitive game element, are indicators of progress that relate an individuals' performance to the performance of others. Thus, they rather serve as feedback and foster the need for competence [46] than fore mostly serve as a tool to determine a winning player. According to Housten et al., another facet of competitiveness focuses on winning as the utmost importance [24]. Thus, this dimension could be included in future studies, e.g. by employing a measurement of hypercompetitiveness [43]. Also, the interactions of trait competitiveness with gamification designs that rule out competition should be tested, whether these designs are detrimental for the perceptions and usage intention of competitive individuals.

Lastly, our research design may lack experimental realism compared to an actual laboratory experiment, as experimental vignette studies may not engage 
participants in the same way a full immersive experiment, where participants would have to behave in a certain manner, would do. Following Aguinis et al., this shortcoming may be tackled with technological advancements, e.g. by using virtual reality simulators to place participants within the situations [2].

\section{Conclusion}

Overall, this study contributes to understanding the interaction of user and gamified system. With maturing of gamification research, asking more fine-grained questions regarding its implementation and design, we believe that future studies should further examine the competitive aspects of gamification. Especially, since competitive game elements such as leaderboards are one of the most commonly employed game elements. Thus, it is imperative to find ways and to understand how to provide the optimal gamification design based on the traits of its users.

\section{References}

[1] Agarwal, R. and Karahanna, E. Time Flies When You're Having Fun: Cognitive Absorption and Beliefs about Information Technology Usage. MIS Quarterly 24, 4 (2000), 665-694.

[2] Aguinis, H. and Bradley, K.J. Best Practice Recommendations for Designing and Implementing Experimental Vignette Methodology Studies. Organizational Research Methods 17, 4 (2014), 351-371.

[3] Aiken, L., West, S., and Reno, R. Multiple regression: Testing and interpreting interactions. Sage, 1991.

[4] Atzmüller, C. and Steiner, P.M. Experimental vignette studies in survey research. Methodology 6, 3 (2010), 128138.

[5] Brouwer, R. When competition is the loser: The indirect effect of intra-team competition on team performance through task complexity, team conflict and psychological safety. Proceedings of the Annual Hawaii International Conference on System Sciences 2016-March, (2016), 13481357.

[6] Bui, A., Veit, D., and Webster, J. Gamification - A Novel Phenomenon or a New Wrapping for Existing Concepts? ICIS 2015 Proceedings, (2015), 1-21.

[7] Cardador, M.T., Northcraft, G.B., and Whicker, J. A theory of work gamification: Something old, something new, something borrowed, something cool? Human Resource Management Review 2, 27 (2015), 353-365.

[8] Christy, K.R. and Fox, J. Leaderboards in a virtual classroom: A test of stereotype threat and social comparison explanations for women's math performance. Computers and Education 78, September (2014), 66-77.

[9] Codish, D. and Ravid, G. Personality Based Gamification: How Differente Personalities Perceive Gamification. Proceedings of the 22nd European Conference on Information Systems (ECIS), (2014), 11.
[10] Davis, F.D., Bagozzi, R.P., and Warshaw, P.R. User Acceptance of Computer Technology: A Comparison of Two Theoretical Models. Management Science 35, 8 (1989), 9821003.

[11] Deterding, S., Dixon, D., Khaled, R., and Nacke, L. From Game Design Elements to Gamefulness:Defining "Gamification." Proceedings of the 15th International Academic MindTrek Conference: Envisioning Future Media Environments, 2011, 9-15.

[12] Deterding, S., Sicart, M., Nacke, L., O'Hara, K., and Dixon, D. Gamification: Using Game DesignElements in Non-Gaming Contexts. CHI ' 11 Extended Abstracts on Human Factors in Computing Systems, 2011, 2425-2428.

[13] Domínguez, A., Saenz-De-Navarrete, J., De-Marcos, L., Fernández-Sanz, L., Pagés, C., and Martínez-Herráiz, J.-J. Gamifying learning experiences: Practical implications and outcomes. Computers and Education 63, (2013), 380-392.

[14] Eickhoff, C., Harris, C.G., de Vries, A.P., and Srinivasan, P. Quality through flow and immersion: gamifying crowdsourced relevance assessments. Proceedings of the 35th international ACM SIGIR conference on Research and development in information retrieval - SIGIR '12, (2012), 871.

[15] Farzan, R., DiMicco, J.M., Millen, D.R., Brownholtz, B., Geyer, W., and Dugan, C. Results from Deploying a Participation Incentive Mechanism within the Enterprise. Proceedings of the SIGCHI Conference on Human Factors in Computing Systems (CHI'08), (2008), 563-572.

[16] Fornell, C. and Larcker, D. Evaluating structural equation models with unobservable variables and measurement error. Journal of marketing research 18, 3 (1981), 39-50.

[17] Hamari, J. and Koivisto, J. "Working out for likes": An empirical study on social influence in exercise gamification. Computers in Human Behavior 50, (2015), 333-347.

[18] Hamari, J. and Koivisto, J. International Journal of Information Management Why do people use gamification services? International Journal of Information Management 35, 4 (2015), 419-431.

[19] Hamari, J., Koivisto, J., and Sarsa, H. Does Gamification Work? - A Literature Review of Empirical Studies on Gamification. The 47th Hawaii International Conference on System Sciences (HICSS), IEEE (2014), 3025-3034.

[20] Hamari, J. and Tuunanen, J. Player types: A metasynthesis. Transactions of the Digital Games Research Association 1, 2 (2014), 29-53.

[21] Hanus, M.D. and Fox, J. Assessing the effects of gamification in the classroom: A longitudinal study on intrinsic motivation, social comparison, satisfaction, effort, and academic performance. Computers and Education 80, (2015), 152-161.

[22] Heijden, H. Van Der. User acceptance of hedonic information systems. MIS Quarterly 28, 4 (2004), 695-704.

[23] Hibbard, D.R. and Buhrmester, D. Competitiveness, Gender, and Adjustment Among Adolescents. Sex Roles 63, 5 (2010), 412-424.

[24] Houston, J.M., Mcintire, S.A., Kinnie, J., and Terry, C. A Factorial Analysis of Scales Measuring Competitiveness. Educational and Psychological Measurement 62, 2 (2002), 284-298. 
[25] Hsu, C.L. and Lin, J.C.C. Acceptance of blog usage: The roles of technology acceptance, social influence and knowledge sharing motivation. Information and Management 45, 1 (2008), 65-74.

[26] Huotari, K. and Hamari, J. A definition for gamification: anchoring gamification in the service marketing literature. Electronic Markets 27, 1 (2017), 21-31.

[27] Jia, Y., Liu, Y., Yu, X., and Voida, S. Designing Leaderboards for Gamification: Perceived Differences Based on User Ranking, Application Domain, and Personality Traits. CHI 2017, (2017), 1949-1960.

[28] Jia, Y., Xu, B., Karanam, Y., and Voida, S. Personalitytargeted Gamification: A Survey Study on Personality Traits and Motivational Affordances. CHI 2016, (2016), 20012013.

[29] Koivisto, J. and Hamari, J. Demographic differences in perceived benefits from gamification. Computers in Human Behavior 35, (2014), 179-188.

[30] Korolov, M. Gamification of the enterprise. PC Advisor, 2012.

http://www.pcadvisor.co.uk/feature/software/gamificationof-enterprise-3380098/.

[31] Landers, R.N., Bauer, K.N., and Callan, R.C. Gamification of task performance with leaderboards: A goal setting experiment. Computers in Human Behavior, (2015), $1-8$.

[32] Landers, R.N. and Landers, A.K. An empirical test of the theory of gamified learning: The effect of leaderboards on time-on-task and academic performance. Simulation \& Gaming 45, 6 (2014), 769-785.

[33] Liu, D., Santhanam, R., and Webster, J. Towards Meaningful Engagement: A Framework for Design and Research of Gamified Information Systems. MIS Quarterly, . [34] Mekler, E.D., Brühlmann, F., Tuch, A.N., and Opwis, K. Towards understanding the effects of individual gamification elements on intrinsic motivation and performance. Computers in Human Behavior, 71 (2017), 525-534.

[35] Miller, A.S., Cafazzo, J.A., and Seto, E. A game plan: Gamification design principles in mHealth applications for chronic disease management Background and significance. Health Informatics Journal 22, 2 (2016), 184-193.

[36] Mollick, E.R. and Rothbard, N. Mandatory Fun: Consent, Gamification and the Impact of Games at Work. The Wharton School Research Paper Series, (2014), 54.

[37] Morschheuser, B., Hamari, J., Koivisto, J., and Maedche, A. Gamified Crowdsourcing: Conceptualization, Literature Review, and Future Agenda. International Journal of Human-Computer Studies, 106 (2017), 26-43.

[38] Nacke, L.E. and Deterding, S. The maturing of gamification research. Computers in Human Behavior, (2017), 1-5.

[39] Nunnally, J. Psychometric theory. McGraw-Hill, New York, 1978.

[40] Pavlou, P., Liang, H., and Xue, Y. Understanding and Mitigating Uncertainty in Online Exchange Relationships: A Principal- Agent Perspective. MIS Quarterly 31, 1 (2007), 105-136.

[41] Preist, C., Massung, E., and Coyle, D. Competing or Aiming to be Average? Normification as a means of engaging digital volunteers. CSCW'14, (2014), 1222-1233.

[42] Ross, S.R., Rausch, M.K., and Canada, K.E.
Competition and Cooperation in the Five-Factor Model: Individual Differences in Achievement Orientation. The Journal of Psychology 137, 4 (2003), 323-337.

[43] Ryckman, R., Hammer, M., Kaczor, L., and Gold, J. Construction of a Hypercompetitive Attitude Scale. Journal of Personality Assessment 55, 3 (1990), 630-639.

[44] Ryckman, R.M., Hammer, M., Kaczor, L.M., and Gold, J.A. Construction of a Personal Development Competitive Attitude Scale. Journal of Personality Assessment 66, 2 (1996), 374-385.

[45] Ryckman, R.M., Libby, C.R., van den Borne, B., Gold, J.A., and Lindner, M.A. Values of Hypercompetitive and Personal Development Competitive Individuals. Journal of Personality Assessment 69, 2 (1997), 271-283.

[46] Sailer, M., Hense, J.U., Mayr, S.K., and Mandl, H. How gamification motivates: An experimental study of the effects of specific game design elements on psychological need satisfaction. Computers in Human Behavior 69, (2017), 371380.

[47] Seaborn, K. and Fels, D.I. Gamification in theory and action: A survey. International Journal of Human-Computer Studies 74, (2015), 14-31.

[48] Seidman, G. Self-presentation and belonging on Facebook: How personality influences social media use and motivations. Personality and Individual Differences 54, (2013), 402-407.

[49] Song, H., Kim, J., Tenzek, K.E., and Lee, K.M. The effects of competition and competitiveness upon intrinsic motivation in exergames. Computers in Human Behavior 29, 4 (2013), 1702-1708.

[50] Spence, J. and Helmreich, R. Achievement-related motives and behavior. In Achievement and achievement motives: Psychological and sociological approaches. Freeman, San Francisco (CA), 1983, 10-74.

[51] Venkatesh, V. Determinants of Perceived Ease of Use: Integrating Control, Intrinsic Motivation, and Emotion into the Technology Acceptance Model. Information Systems Research 11, 4 (2000), 342-365.

[52] Venkatesh, V. and Morris, M. Why don't men ever stop to ask for directions? Gender, social influence, and their role in technology acceptance and usage behavior. MIS Quarterly, 2000, 115-139.

[53] Vorderer, P., Hartmann, T., and Klimmt, C. Explaining the enjoyment of playing video games: the role of competition. ICEC '03 Proceedings of the second international conference on Entertainment computing, February (2003), 2-10.

[54] Yee, N. Motivations for Play in Online Games. CyberPsychology \& Behavior 9, 6 (2006), 772-775.

[55] Yee, N., Ducheneaut, N., and Nelson, L. Online Gaming Motivations Scale: Development and Validation. Chi'12, (2012), 1-4.

[56] Zichermann, G. and Cunningham, C. Gamification by design: Implementing game mechanics in web and mobile apps. " O’Reilly Media, Inc.," 2011.

[57] Zuckerman, O. and Gal-Oz, A. Deconstructing gamification: evaluating the effectiveness of continuous measurement, virtual rewards, and social comparison for promoting physical activity. Personal and ubiquitous computing 18, 7 (2014), 1705-1719. 